\title{
Pontas de pulverização e eletrificação das gotas na deposição da calda em plantas de crisântemo
}

\author{
Marina Elisei Serra(1), Aldemir Chaim ${ }^{(2)}$ e Carlos Gilberto Raetano(1)
}

\begin{abstract}
(1)Universidade Estadual Paulista, Faculdade de Ciências Agronômicas, Departamento de Produção Vegetal, Rua José Barbosa de Barros, № 1.780, CEP 18610-307 Botucatu, SP. E-mail: marina.serra@gmail.com, raetano@fca.unesp.br (2)Embrapa Meio Ambiente, Rodovia CampinasMogi Mirim, Km 127,5, CEP 13820-000 Jaguariúna, SP. E-mail: aldemir@cnpma.embrapa.br
\end{abstract}

\begin{abstract}
Resumo - O objetivo deste trabalho foi avaliar a deposição das gotas de pulverização, dotadas de carga elétrica (eletrostática), em comparação à técnica de pulverização convencional em crisântemo, com uso de diferentes pontas de pulverização. $\mathrm{O}$ experimento foi conduzido em delineamento inteiramente ao acaso, com oito tratamentos: combinação das pontas TXVK-3, AXI 110015, AXI 12002 TWIN e AXI 11003, com duas técnicas de pulverização (com e sem eletrostática), e quatro repetições. Cada repetição foi representada por 12 plantas, às quais foram afixados papéis do tipo mata-borrão na superfície abaxial e adaxial dos folíolos, e em duas posições da planta: ápice e base. Um corante marcador (Rodamina B) foi pulverizado na proporção de $5 \mathrm{~g}$ por $100 \mathrm{~L}$ d'água em cada um dos tratamentos. Os depósitos do marcador foram quantificados por fluorometria. As pontas com gotas de menor diâmetro mediano volumétrico (TXVK-3 e AXI 110015) apresentaram maiores depósitos na superfície abaxial da folha, quando se utilizou a pulverização eletrostática. Esse fato não foi observado, quando foram pulverizadas gotas com maior diâmetro mediano volumétrico e desprovidas de carga elétrica, nas diferentes partes da planta.
\end{abstract}

Termos para indexação: Dendranthema grandiflora, eletrostática, plantas ornamentais, tecnologia de aplicação.

\section{Nozzles and droplets with electric charge on spray deposition in chrysanthemum plants}

\begin{abstract}
The aim of this work was to evaluate the spray deposition with electric charge (electrostatic), compared to conventional application technique (without electric charge), on chrysanthemum plants using different spray nozzle types. The experiment was carried out entirely at random, with eight treatments: TXVK-3, AXI 110015, AXI 12002 TWIN and AXI 11003 spray nozzles were combined in two spraying techniques (with and without electrostatic) and four replications. Each replicate was represented by 12 chrysanthemum plants. Blotting paper was placed on the abaxial and adaxial surfaces of two leaves, in different positions of the plants: top and bottom.

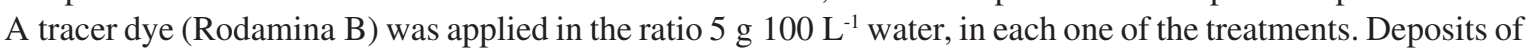
the tracer dye were quantified by fluorometry. The spray nozzles with droplets of the smallest volumetric medianum diameter (TXVK-3 e AXI 110015) showed greater deposits in the abaxial surface of the leaves, when the electrostatic spraying was used. This fact was not observed, when droplets of the greatest volumetric medianum diameter and without electric charge were deposited in different parts on chrysanthemum plant.
\end{abstract}

Index terms: Dendranthema grandiflora, electrostatic, ornamental plants, application technology.

\section{Introdução}

O crisântemo é uma das mais importantes plantas ornamentais comercializadas no mundo, principalmente na Europa, Japão e Estados Unidos da América; no Brasil, vem se destacando tanto no mercado interno, como no externo (Bueno et al., 2003). A exportação dessa planta é incipiente no Brasil, ao redor de 2 a $5 \%$. Isto se deve, principalmente, ao fato de a qualidade do produto nacional não atender aos padrões fitossanitários exigidos pelos países importadores (Silveira, 1998). Entre os fatores que têm contribuído para o baixo padrão fitossanitário do produto nacional estão o ataque de ácaros e insetos-praga como tripes e pulgões (Bergman et al., 1996).

Com o aumento da produção intensiva de flores, principalmente em cultivo protegido, tem-se favorecido 
o aparecimento dessas pragas, que provocam prejuízos econômicos à cultura. $\mathrm{O}$ crescimento de áreas cultivadas com crisântemo no Brasil e os problemas enfrentados com pragas nessa cultura têm despertado interesse para a redução dos impactos ambientais, bem como forte demanda por alternativas que conduzam à sua sustentabilidade (Kiyuna et al., 2004).

Christofoletti (1999) descreve que a aplicação é um processo em que se coloca o produto químico no alvo. Teoricamente, quanto maior a quantidade de produto depositada na superfície, maior poderá ser a sua ação. Assim, a aplicação de um determinado produto químico pode ser otimizada em termos de eficiência, expressa pela relação percentual entre a quantidade de produto depositada no alvo e a quantidade de produto emitida pela máquina.

No Brasil, a aplicação de produtos fitossanitários à cultura de crisântemo, em vaso ou para corte, excede a $800 \mathrm{~L} \mathrm{ha}^{-1}$ e utiliza equipamentos adaptados daqueles usados na agricultura, sem qualquer controle da pressão de trabalho. No entanto, as pulverizações em lavouras, tal como se pratica hoje, têm se caracterizado por considerável desperdício de energia, uso inadequado de produtos químicos e significativa contaminação do ambiente (Matthews, 2000). Neste contexto, os métodos de aplicação de produtos fitossanitários, empregados atualmente, revelam-se extremamente desperdiçadores e pouco adequados ao novo conceito de sustentabilidade (Chaim et al., 2002, 2006).

O método de pulverização eletrostática trata da eletrificação das gotas, a fim de que sejam fortemente atraídas pela planta e que, dessa forma, atinjam áreas ou alvos que dificilmente seriam atingidos pelo processo de pulverização com bicos hidráulicos convencionais. O melhor processo eletrostático para bicos hidráulicos é descrito por Chaim (2006) como sistema de carga de gotas por indução eletrostática com eletrificação direta. Portanto, os estudos que visam redução dos volumes de pulverização atualmente praticados, associados à tecnologias que propiciem melhor distribuição do produto aplicado nessa cultura, e que minimizem a exposição dos aplicadores e a contaminação do ambiente justificam a realização deste trabalho.

O trabalho teve como objetivo avaliar e comparar a deposição de gotas de pulverização eletrostática com a convencional, com uso de diferentes pontas de pulverização sobre as superfícies da folha, em diferentes partes da planta do crisântemo.

\section{Material e Métodos}

O experimento foi instalado em casa de vegetação, em condições controladas de temperatura $\left(23 \pm 2^{\circ} \mathrm{C}\right)$ e de umidade relativa do ar $(78 \pm 2 \%)$. Os vasos foram trazidos para o Laboratório de Tecnologia de Aplicação de Defensivos Agrícolas, da Faculdade de Ciências Agronômicas (FCA) da Unesp, Campus de Botucatu, SP, para se realizar a aplicação e, após a pulverização, foram levados de volta à casa de vegetação.

Plantas de crisântemo, Dendranthema grandiflora, da variedade Rage, aos 60 dias após o plantio (DAP), plantadas em vasos de plástico número 15 , com 1,3 L de substrato, foram cedidas por uma empresa comercial, com sede em Holambra II, Município de Paranapanema, SP, e trazidas para a casa de vegetação da FCA-Unesp.

Nessa ocasião, as plantas, pertencentes a um lote de mesma idade, apresentavam botões florais ainda fechados e foram irrigadas duas vezes ao dia, pela manhã e à tarde, sem adição de qualquer fertilizante durante a condução do experimento. No modo como são conduzidas na empresa, as plantas ficam suspensas em tijolos de barro à densidade de aproximadamente 110 mil plantas por hectare.

No experimento, utilizou-se um protótipo de pulverizador costal, com acionamento manual desenvolvido pela Embrapa Meio Ambiente.

Uma barra com três bicos, com distância de $0,35 \mathrm{~m}$ entre os bicos, foi acoplada ao pulverizador equipado com fonte de alta tensão de $40 \mathrm{kV}$, alimentado por bateria de $6 \mathrm{~V}$ (4 pilhas grandes do tipo D). O pulverizador possui uma válvula reguladora de pressão e trabalhou a $207 \mathrm{kPa}$ com eletrificação direta, em que a indução ocorre entre a planta e o jato de gotas mantido em alta tensão, e apresenta deposição muito semelhante à do antigo "Electrodyn" (Araújo et al., 2002). Todos os componentes do equipamento foram feitos de material isolante (plástico), a fim de se evitar descarga elétrica ao aplicador. A pressão de trabalho foi aferida, indiretamente, pela vazão nominal das respectivas pontas de pulverização, comparada à vazão estabelecida pelos fabricantes.

$\mathrm{O}$ delineamento experimental utilizado foi o inteiramente ao acaso, com oito tratamentos e quatro repetições, e cada repetição foi representada por 12 plantas. Em cada uma das plantas, foram colocados papéis do tipo mata-borrão com $1,5 \times 2 \mathrm{~cm}$, nas superfícies abaxial e adaxial dos folíolos, em duas posições da planta: ápice e base, no total de quatro papéis por planta. 
Em cada tratamento, foram dispostas seis fileiras de oito plantas em ziguezague, com distância de $0,30 \mathrm{~m}$ de centro a centro entre os vasos, conforme a recomendação dos produtores de flores da região de Holambra II. Os tratamentos estão apresentados na Tabela 1.

A pulverização foi realizada 5 dias após a aclimatação dos vasos no Departamento de Produção Vegetal, aos 65 dias após o plantio (DAP). A pulverização foi realizada em única passada do aplicador pelas três primeiras fileiras de plantas, tendo-se procedido da mesma forma sobre as outras três fileiras de plantas, e começou a 2 m de distância antes do conjunto de plantas, com o bocal mantido a $0,20 \mathrm{~m}$ de altura delas. Essa distância foi necessária para a sobreposição mínima entre jatos adjacentes, para obtenção de uniformidade de distribuição da calda, bem como para garantir a quantidade mínima de carga para atração das gotas $4 \mathrm{mC} \mathrm{L}^{-1}$ (Chaim, 2006). Para a pulverização eletrostática, foi montado um sistema para aterramento dos vasos. Para a pulverização convencional, foi utilizado o mesmo equipamento, com o sistema eletrostático desligado.

A calda de pulverização foi preparada com o corante Rodamina $\mathrm{B}$, à concentração de um grama de corante para vinte litros de água. Na pulverização, foram utilizadas quatro pontas diferentes: AXI 110015, AXI 11003, AXI 12002 TWIN e TXVK-3 e dois métodos de pulverização, convencional e eletrostático (Tabela 1).

A velocidade de deslocamento do aplicador foi medida com o auxílio de um cronômetro $\left(2,7 \mathrm{~km} \mathrm{~h}^{-1}\right)$, e o volume de pulverização do equipamento variou conforme a vazão de cada ponta na mesma pressão de trabalho. A seleção de tais pontas de pulverização se deve ao fato de que o volume de pulverização e o tamanho das gotas influenciam na quantidade de carga adquirida pelas gotas. A pulverização foi realizada em um único dia, e os papéis foram coletados sem separação por planta, dentro de um mesmo tratamento.

Tabela 1. Tratamentos para avaliação da deposição da pulverização, em plantas de crisântemo, com pressão de trabalho de $207 \mathrm{kPa}$ em todas as pontas.

\begin{tabular}{|c|c|c|c|c|c|c|}
\hline Tratamento & Pontas & $\begin{array}{c}\text { Forma do } \\
\text { Jato }\end{array}$ & Eletrostática & $\begin{array}{l}\text { Parte da planta } \rightarrow \\
\text { parte da folha }\end{array}$ & $\begin{array}{c}\text { Volume de aplicação } \\
\left(\mathrm{L} \mathrm{ha}^{-1}\right)\end{array}$ & $\begin{array}{c}\mathrm{DMV}^{(1)} \\
(\mu \mathrm{m})\end{array}$ \\
\hline $\mathrm{T} 1$ & AXI 110015 & Plano & Sem & $\begin{array}{l}\text { Ápice } \rightarrow \text { Adaxial } \\
\text { Ápice } \rightarrow \text { Abaxial } \\
\text { Base } \rightarrow \text { Adaxial } \\
\text { Base } \rightarrow \text { Abaxial }\end{array}$ & 200 & 143 \\
\hline $\mathrm{T} 2$ & AXI 110015 & Plano & Com & $\begin{array}{l}\text { Ápice } \rightarrow \text { Adaxial } \\
\text { Ápice } \rightarrow \text { Abaxial } \\
\text { Base } \rightarrow \text { Adaxial } \\
\text { Base } \rightarrow \text { Abaxial }\end{array}$ & 200 & 143 \\
\hline T3 & AXI 12002 TWIN & Plano duplo & Sem & $\begin{array}{l}\text { Ápice } \rightarrow \text { Adaxial } \\
\text { Ápice } \rightarrow \text { Abaxial } \\
\text { Base } \rightarrow \text { Adaxial } \\
\text { Base } \rightarrow \text { Abaxial }\end{array}$ & 300 & $-^{(2)}$ \\
\hline T4 & AXI 12002 TWIN & Plano duplo & Com & $\begin{array}{l}\text { Apice } \rightarrow \text { Adaxial } \\
\text { Ápice } \rightarrow \text { Abaxial } \\
\text { Base } \rightarrow \text { Adaxial } \\
\text { Base } \rightarrow \text { Abaxial }\end{array}$ & 300 & - \\
\hline T5 & TXVK-3 & Cônico vazio & Sem & $\begin{array}{l}\text { Ápice } \rightarrow \text { Adaxial } \\
\text { Ápice } \rightarrow \text { Abaxial } \\
\text { Base } \rightarrow \text { Adaxial } \\
\text { Base } \rightarrow \text { Abaxial }\end{array}$ & 100 & 123 \\
\hline T6 & TXVK-3 & Cônico vazio & Com & $\begin{array}{l}\text { Ápice } \rightarrow \text { Adaxial } \\
\text { Ápice } \rightarrow \text { Abaxial } \\
\text { Base } \rightarrow \text { Adaxial } \\
\text { Base } \rightarrow \text { Abaxial }\end{array}$ & 100 & 123 \\
\hline $\mathrm{T} 7$ & AXI 11003 & Plano & Sem & $\begin{array}{l}\text { Ápice } \rightarrow \text { Adaxial } \\
\text { Ápice } \rightarrow \text { Abaxial } \\
\text { Base } \rightarrow \text { Adaxial } \\
\text { Base } \rightarrow \text { Abaxial }\end{array}$ & 400 & 199 \\
\hline T8 & AXI 11003 & Plano & Com & $\begin{array}{l}\text { Ápice } \rightarrow \text { Adaxial } \\
\text { Ápice } \rightarrow \text { Abaxial } \\
\text { Base } \rightarrow \text { Adaxial } \\
\text { Base } \rightarrow \text { Abaxial }\end{array}$ & 400 & 199 \\
\hline
\end{tabular}

${ }^{(1)}$ Diâmetro mediano volumétrico, informado pelo fabricante. ${ }^{(2)}$ Em determinação pelo fabricante. 
Os papéis do tipo mata-borrão foram coletados, levados ao Laboratório de Tecnologia de Aplicação da Embrapa Meio Ambiente, em Jaguariúna, SP, e separados em quatro lotes de aproximadamente $1.000 \mathrm{mg}$ de amostras de papel mata-borrão. A extração e análise foi realizada conforme Chaim et al. (2003, 2004).

Como cada tipo de ponta aplicou volume de calda compatível com sua vazão e velocidade de pulverização, diferentes doses do corante Rodamina B foram pulverizadas por hectare. Assim, os valores dos resíduos encontrados foram transformados para um volume equivalente a $100 \mathrm{~L} \mathrm{ha}^{-1}$ para serem comparados.

Para análise dos dados, os tratamentos foram distribuídos no esquema fatorial $4 \times 2 \times 2$ (quatro tipos de pontas combinadas a duas técnicas de pulverização, em duas posições na planta). Os valores médios dos depósitos de Rodamina B para as interações entre fatores: ponta de pulverização, técnica de aplicação e posição na planta estão apresentados separadamente nas Tabelas 2,3 e 4 . Os dados foram submetidos à análise de variância pelo teste $\mathrm{F}$, e as médias dos tratamentos foram comparadas pelo teste $\mathrm{t}$, a $5 \%$ de probabilidade.

\section{Resultados e Discussão}

A deposição do corante com a ponta de pulverização AXI 11003, no ápice da planta, não diferiu nos tratamentos com e sem eletrostática, em ambas as superfícies foliares (Tabela 2). Na base da planta, constatou-se diferença entre os valores dos depósitos da pulverização na superfície adaxial da folha, que foram maiores com a técnica de pulverização eletrostática. $\mathrm{Na}$ superfície abaxial da folha, não foram constatadas diferenças entre tratamentos nas diferentes técnicas de pulverização com a ponta AXI 11003.

Considerando-se que: a taxa de eletrificação das gotas decresce, à medida que o diâmetro mediano volumétrico (DMV) aumenta; que este fenômeno é inerente a todas as técnicas de eletrificação de gotas (Almekinders et al., 1992); e, ainda, que o DMV das gotas produzidas pela ponta AXI 11003 equivale a $199 \mu \mathrm{m}$, supõe-se que a menor taxa de eletrificação aliada ao maior volume aplicado (400 $\left.\mathrm{L} \mathrm{ha}^{-1}\right)$ e à maior vazão dessa ponta, entre as pontas de pulverização em teste, tenham sido decisivos para não terem sido constatadas diferenças nos depósitos com e sem eletrostática, no ápice da planta.

Quando foi utilizada a ponta AXI 12002 TWIN, a pulverização eletrostática apresentou deposição superior à convencional apenas na superfície adaxial do ápice das plantas. Isso, provavelmente, também se deve ao maior volume (300 $\left.\mathrm{L} \mathrm{ha}^{-1}\right)$ e DMV dessa ponta, em relação às pontas TXVK-3 e AXI 110015.

Não há dúvida de que o DMV das gotas influencia na deposição da pulverização em diferentes partes da planta de crisântemo. Nesse experimento, pôde-se constatar que as folhas do ápice da planta, superfície adaxial das folhas, receberam maior quantidade dos depósitos do corante, em relação àquelas da posição basal, para todos os tratamentos. Este fato, provavelmente, está relacionado ao incremento dos depósitos com a pulverização eletrostática,

Tabela 2. Valores médios de deposição do corante Rodamina B $\left(\mu \mathrm{g} \mathrm{cm}^{-2}\right)$, em presença ou não da eletrostática, nas superfícies foliares do crisântemo, para a interação ponta de pulverização x posição na planta ${ }^{(1)}$.

\begin{tabular}{|c|c|c|c|c|c|}
\hline \multirow[t]{2}{*}{ Ponta } & \multirow[t]{2}{*}{ Posição na planta } & \multirow[t]{2}{*}{ Superfície da folha } & \multicolumn{2}{|c|}{ Eletrostática } & \multirow[t]{2}{*}{ DMS } \\
\hline & & & Com & Sem & \\
\hline \multirow[t]{4}{*}{ AXI 11003} & Ápice & Abaxial & $3,35 \mathrm{a}$ & $2,03 a$ & 2,88 \\
\hline & & Adaxial & $24,43 \mathrm{a}$ & $23,88 \mathrm{a}$ & 2,88 \\
\hline & Base & Abaxial & $1,63 \mathrm{a}$ & $0,75 \mathrm{a}$ & 2,88 \\
\hline & & Adaxial & $9,20 \mathrm{a}$ & $5,20 \mathrm{~b}$ & 2,88 \\
\hline \multirow[t]{4}{*}{ AXI 110015} & Ápice & Abaxial & $9,23 \mathrm{a}$ & $1,35 \mathrm{~b}$ & 2,88 \\
\hline & & Adaxial & $27,43 a$ & $21,20 \mathrm{~b}$ & 2,88 \\
\hline & Base & Abaxial & $1,35 \mathrm{a}$ & $0,93 a$ & 2,88 \\
\hline & & Adaxial & $6,68 \mathrm{a}$ & $5,13 \mathrm{a}$ & 2,88 \\
\hline \multirow[t]{4}{*}{ AXI 12002 TWIN } & Ápice & Abaxial & $1,90 \mathrm{a}$ & $3,13 \mathrm{a}$ & 2,88 \\
\hline & & Adaxial & $22,60 \mathrm{a}$ & $18,23 \mathrm{~b}$ & 2,88 \\
\hline & Base & Abaxial & $0,40 \mathrm{a}$ & $0,50 \mathrm{a}$ & 2,88 \\
\hline & & Adaxial & $4,00 \mathrm{a}$ & $4,88 \mathrm{a}$ & 2,88 \\
\hline \multirow[t]{4}{*}{ TXVK-3 } & Ápice & Abaxial & $8,13 a$ & $3,18 b$ & 2,88 \\
\hline & & Adaxial & $93,48 \mathrm{a}$ & $37,05 \mathrm{~b}$ & 2,88 \\
\hline & Base & Abaxial & $2,58 \mathrm{a}$ & $1,25 \mathrm{a}$ & 2,88 \\
\hline & & Adaxial & $21,53 \mathrm{a}$ & $4,05 \mathrm{~b}$ & 2,88 \\
\hline
\end{tabular}

${ }^{(1)}$ Médias seguidas por letras iguais, nas linhas, não diferem entre si pelo teste t, a $5 \%$ de probabilidade. 
comparativamente aos depósitos obtidos com gotas desprovidas de carga elétrica (Hislop, 1988; Kabashima et al., 1995), além de o uso da força eletrostática reduzir a capacidade das gotas de penetrar no dossel de plantas densas (Almekinders et al., 1992).

A ponta de pulverização TXVK-3, com gotas de menor DMV e providas de carga elétrica, proporcionou níveis três vezes maiores de depósitos, em relação às demais pontas de pulverização no ápice da planta (Tabela 3). Da mesma forma, a deposição da pulverização na superfície adaxial dos folíolos, na base da planta, com a ponta TXVK-3, foi significativamente maior, seguida pelas pontas AXI 11003, AXI 110015 e AXI 12002 TWIN.
O aumento da vazão de pulverização diminui a intensidade da carga das gotas, e o aumento da carga aumenta significativamente a deposição da pulverização, em alvos artificiais esféricos (Chaim et al., 2002). Isso pode ter contribuído para o melhor desempenho da ponta TXVK-3, na base da planta, pela menor vazão entre as pontas, o que proporcionou depósitos significativamente maiores em relação às pontas AXI 11003, AXI 110015 e AXI 12002 TWIN, que apresentaram valores decrescentes dos depósitos nessa ordem (Tabela 4).

Os depósitos com a ponta AXI 110015 e gotas providas de carga elétrica foram maiores no ápice da planta, nas duas superfícies da folha; porém na base da planta não foi detectada diferença entre os tratamentos com eletrostática e convencional. Isso pode ter ocorrido

Tabela 3. Valores médios de deposição do corante Rodamina B $\left(\mu \mathrm{g} \mathrm{cm}^{-2}\right)$, com uso de diferentes tipos de ponta de pulverização, nas superfícies abaxial e adaxial de folhas de crisântemo, para a interação técnica de pulverização x posição na planta(1).

\begin{tabular}{|c|c|c|c|c|c|c|c|}
\hline \multirow[t]{2}{*}{ Eletrostática } & \multirow{2}{*}{$\begin{array}{c}\text { Posição na } \\
\text { planta }\end{array}$} & \multirow[t]{2}{*}{ Superfície da folha } & \multicolumn{4}{|c|}{ Tipos de ponta } & \multirow[t]{2}{*}{ DMS } \\
\hline & & & AXI 11003 & AXI 110015 & AXI 12002 TWIN & TXVK-3 & \\
\hline \multirow[t]{4}{*}{ Com } & \multirow[t]{2}{*}{ Ápice } & Abaxial & $3,35 \mathrm{~b}$ & $9,23 \mathrm{a}$ & $1,90 \mathrm{~b}$ & $8,13 \mathrm{a}$ & 3,80 \\
\hline & & Adaxial & $24,43 b c$ & $27,43 b$ & $22,60 \mathrm{c}$ & $93,48 \mathrm{a}$ & 3,80 \\
\hline & \multirow[t]{2}{*}{ Base } & Abaxial & $1,63 \mathrm{a}$ & $1,35 \mathrm{a}$ & $0,40 \mathrm{a}$ & $2,58 \mathrm{a}$ & 3,80 \\
\hline & & Adaxial & $9,20 \mathrm{~b}$ & $6,68 \mathrm{bc}$ & $4,00 \mathrm{c}$ & $21,53 \mathrm{a}$ & 3,80 \\
\hline \multirow[t]{4}{*}{ Sem } & \multirow[t]{2}{*}{ Ápice } & Abaxial & $2,03 a$ & $2,20 \mathrm{a}$ & $3,13 a$ & $3,18 \mathrm{a}$ & 3,80 \\
\hline & & Adaxial & $23,88 \mathrm{~b}$ & $21,20 \mathrm{bc}$ & $18,23 \mathrm{c}$ & $37,05 \mathrm{a}$ & 3,80 \\
\hline & \multirow[t]{2}{*}{ Base } & Abaxial & $0,75 \mathrm{a}$ & $0,93 \mathrm{a}$ & $0,50 \mathrm{a}$ & $1,25 \mathrm{a}$ & 3,80 \\
\hline & & Adaxial & $5,20 \mathrm{a}$ & $5,13 \mathrm{a}$ & $4,88 \mathrm{a}$ & $4,05 \mathrm{a}$ & 3,80 \\
\hline
\end{tabular}

${ }^{(1)}$ Médias seguidas por letras iguais, nas linhas, não diferem entre si pelo teste de Tukey, a 5\% de probabilidade.

Tabela 4. Valores médios de deposição do corante Rodamina B $\left(\mu \mathrm{g} \mathrm{cm}^{-2}\right)$, nas superfícies abaxial e adaxial da folha de crisântemo, para as interações: ponta x técnica de pulverização; técnica de pulverização x posição na planta ${ }^{(1)}$.

\begin{tabular}{|c|c|c|c|c|c|}
\hline \multirow[t]{2}{*}{ Ponta } & \multirow[t]{2}{*}{ Eletrostática } & \multirow[t]{2}{*}{ Posição na planta } & \multicolumn{2}{|c|}{ Superfície da folha } & \multirow[t]{2}{*}{ DMS } \\
\hline & & & Abaxial & Adaxial & \\
\hline \multirow[t]{5}{*}{ AXI 11003} & Com & Ápice & $3,35 \mathrm{bA}$ & $24,43 \mathrm{aA}$ & 3,05 \\
\hline & & Base & $1,63 \mathrm{bA}$ & $9,20 \mathrm{aB}$ & 3,05 \\
\hline & DMS & - & 3,07 & 3,07 & - \\
\hline & Sem & Ápice & $2,03 \mathrm{bA}$ & $23,88 \mathrm{aA}$ & 3,05 \\
\hline & & Base & $0,75 \mathrm{bA}$ & $5,20 \mathrm{aB}$ & 3,05 \\
\hline \multirow[t]{5}{*}{ AXI 110015} & Com & Ápice & $9,23 \mathrm{bA}$ & $27,43 \mathrm{aA}$ & 3,05 \\
\hline & & Base & $1,35 \mathrm{bB}$ & $6,68 \mathrm{aB}$ & 3,05 \\
\hline & DMS & - & 3,07 & 3,07 & - \\
\hline & Sem & Ápice & $2,20 \mathrm{bA}$ & $21,20 \mathrm{aA}$ & 3,05 \\
\hline & & Base & $0,93 \mathrm{bA}$ & $5,13 \mathrm{aB}$ & 3,05 \\
\hline \multirow[t]{5}{*}{ AXI 12002 TWIN } & Com & Ápice & $1,90 \mathrm{bA}$ & $22,60 \mathrm{aA}$ & 3,05 \\
\hline & & Base & $0,40 \mathrm{bA}$ & $4,00 \mathrm{aB}$ & 3,05 \\
\hline & DMS & - & 3,07 & 3,07 & - \\
\hline & Sem & Ápice & $3,13 \mathrm{bA}$ & $18,23 \mathrm{aA}$ & 3,05 \\
\hline & & Base & $0,50 \mathrm{bA}$ & $4,88 \mathrm{aB}$ & 3,05 \\
\hline \multirow[t]{5}{*}{ TXVK-3 } & Com & Ápice & $8,13 \mathrm{bA}$ & $93,48 \mathrm{aA}$ & 3,05 \\
\hline & & Base & $2,58 \mathrm{bB}$ & $21,53 \mathrm{aB}$ & 3,05 \\
\hline & DMS & - & 3,07 & 3,07 & - \\
\hline & Sem & Ápice & $3,18 \mathrm{bA}$ & $37,05 \mathrm{aA}$ & 3,05 \\
\hline & & Base & $1,25 \mathrm{aA}$ & $4,05 \mathrm{aB}$ & 3,05 \\
\hline
\end{tabular}

${ }^{(1)}$ Médias seguidas por letras iguais, minúsculas nas linhas e maiúsculas nas colunas, dentro de cada técnica de aplicação, não diferem entre si pelo teste $\mathrm{t}$, a $5 \%$ de probabilidade, em cada ponta de pulverização. 
pelo fato de o DMV das gotas produzidas por essa ponta estar na mesma classe de tamanho (gotas finas) daquelas produzidas pela ponta TXVK-3, porém o volume de pulverização maior (200 L ha-1) com a ponta AXI 110015 foi decisivo para o incremento dos depósitos na superfície abaxial, no ápice da planta.

Ao se utilizar a pulverização convencional (gotas desprovidas de carga elétrica), tanto no ápice quanto na base da planta, não foram constatadas diferenças na deposição do corante na superfície abaxial das folhas, com diferentes pontas. Este fato também foi constatado na superfície adaxial da folha, na base da planta.

$\mathrm{O}$ diâmetro mediano volumétrico (DMV) das gotas produzidas pelas pontas de pulverização AXI 11003 e AXI 12002 TWIN, provavelmente, influenciou a quantidade do depósito na superfície abaxial das folhas; não houve diferença na deposição do corante Rodamina B nem mesmo no ápice da planta, conforme a Tabela 4, em que se observa que essas pontas apresentaram menor deposição na superfície abaxial da folha, no ápice da planta, quando a pulverização foi realizada com gotas providas de carga elétrica. Houve maior deposição na superfície abaxial das folhas do ápice, em relação às folhas da base da planta, com as pontas AXI 110015 e TXVK-3 e gotas providas de carga elétrica.

O uso da eletrostática como incremento na deposição de pulverizações (Hislop, 1988; Chaim et al., 2002) foi ratificado no presente trabalho, especialmente para as pontas de pulverização TXVK-3 e AXI 110015, quando se avaliou o ápice das plantas (Tabela 4). Na parte basal da planta, a ponta TXVK-3 apresentou melhor desempenho e proporcionou depósitos significativamente maiores, em comparação às demais pontas de pulverização (Tabela 4).

Além da possibilidade de redução nos volumes de caldas aplicadas, a eletrostática pode propiciar significativa redução das doses normalmente aplicadas (Chaim, 2006), diminuir o custo de produção e melhorar a qualidade dos produtos, nesse caso, a sanidade de plantas ornamentais.

Os resultados obtidos no presente trabalho e em outros anteriormente citados (Kabashima et al., 1995; Chaim et al., 2002; Schroder \& Loeck, 2006) revelam que pode haver diminuição da dosagem dos produtos fitossanitários aplicados, e, assim, promover-se redução do risco de contaminação do operador e do meio ambiente. Esses trabalhos mostram, ainda, que o sistema de pulverização eletrostática, de modo geral, é recomendável para a aplicação de produtos fitossanitários, pois apresenta melhor deposição na quantidade de produto, quando são utilizadas pontas que produzem gotas com menor DMV. Em pulverizações com equipamentos convencionais (desprovidos de carga elétrica), o uso de pontas com menor DMV pode aumentar o potencial de deriva. No entanto, quando providas de carga elétrica, o risco de deriva é menor, em decorrência da atração das gotas pelas plantas.

Os volumes de pulverização atualmente utilizados pelos produtores de crisântemo, no controle fitossanitário dessa cultura, independentemente da forma de condução (vaso ou corte), são superiores a $800 \mathrm{~L} \mathrm{ha}^{-1}$. No presente trabalho, os volumes de 100 a $400 \mathrm{~L} \mathrm{ha}^{-1}$ não foram suficientes para atingir a capacidade máxima de retenção foliar (escorrimento), quando as pulverizações foram realizadas aos 65 DAP, em plantas de crisântemo.

$O$ resultado de teste preliminar conduzido no Laboratório de Tecnologia de Aplicação de Defensivos, da FCA-Unesp, com a imersão da parte aérea do crisântemo em água, aos 65 DAP, apontaram que a média do volume máximo de retenção de água pelas plantas foi de aproximadamente $1.800 \mathrm{~L} \mathrm{ha}^{-1}$ (Tabela 5).

O aumento nos depósitos da pulverização, na base das plantas de crisântemo, pode ser obtido com a associação da assistência de ar às pontas hidráulicas

Tabela 5. Taxa de retenção máxima de água pelas plantas de crisântemo, aos 60 dias após o plantio.

\begin{tabular}{|c|c|c|c|c|c|}
\hline \multirow[t]{2}{*}{ Planta } & \multirow[t]{2}{*}{ Taxa de retenção $(\mathrm{mL})$} & \multicolumn{2}{|c|}{ Área $\left(\mathrm{cm}^{2}\right)$} & \multirow[t]{2}{*}{ Retenção/área $\left(\mathrm{mL} \mathrm{cm}^{-2}\right)$} & \multirow[t]{2}{*}{ Retenção/área $\left(\mathrm{L} \mathrm{ha}^{-1}\right)$} \\
\hline & & Foliar & Ramos e flores & & \\
\hline Planta 1 & 43,05 & 2.131 & 499,21 & 0,1636 & 1.636 \\
\hline Planta 2 & 42,06 & 2.008 & 509,55 & 0,0167 & 1.670 \\
\hline Planta 3 & 48,79 & 2.092 & 494,41 & 0,0189 & 1.885 \\
\hline Planta 4 & 46,47 & 2.446 & 490,83 & 0,0164 & 1.582 \\
\hline Planta 5 & 47,77 & 2.385 & 526,01 & 0,0158 & 1.640 \\
\hline Planta 6 & 63,95 & 2.382 & 589,04 & 0,0215 & 2.152 \\
\hline Planta 7 & 49,94 & 2.392 & 549,79 & 0,0170 & 1.697 \\
\hline Planta 8 & 63,37 & 2.569 & 586,05 & 0,2009 & 2.008 \\
\hline Média & 45,18 & 2.300 & 530,61 & 0,0157 & 1.784 \\
\hline
\end{tabular}


que produzem gotas finas e muito finas, providas de carga elétrica. Assim, podem-se reduzir ainda mais os volumes de pulverização, em comparação aos utilizados no presente trabalho, e reduzir a contaminação do meio ambiente.

\section{Conclusões}

1. A pulverização eletrostática promove deposição maior ou igual das gotas, na superfície adaxial das folhas do crisântemo, em comparação à pulverização com gotas desprovidas de carga elétrica.

2. Quando utilizada a pulverização eletrostática, os valores médios dos depósitos do corante Rodamina B, na superfície abaxial das folhas, variam de acordo com o diâmetro mediano volumétrico das gotas produzidas por cada ponta de pulverização.

3. As pontas AXI 12002 TWIN e AXI 11003 não se mostram eficientes na deposição de gotas, na superfície abaxial das folhas do ápice da planta, com a pulverização eletrostática.

\section{Agradecimentos}

À Coordenação de Aperfeiçoamento de Pessoal de Nível Superior, por concessão de bolsa; à Empresa Steltenpool Flores e Frutas, pelo material fornecido e apoio para a realização deste trabalho de pesquisa.

\section{Referências}

ALMEKINDERS, H.; OZKAN, H.E.; REICHARD, D.L.; CARPENTER, T.G.; BRAZEE, R.D. Spray deposit patterns of an electrostatic atomizer. Transactions of the ASAE, v.35, p.13611367, 1992.

ARAÚJO, L.H.A.; SANTOS, R.F.; SOUSA, S.L.; QUEIROGA, V.P.; LIMA, N.J. Avaliação da mistura endosulfan com óleos vegetais para o controle do bicudo-do-algodoeiro, Anthonomus grandis Boheman, 1843 (Coleoptera: Curculionidae). Campina Grande: Embrapa Algodão, 2002. 7p. (Embrapa Algodão. Comunicado Técnico, 151).
BERGMAN, E.C.; IMENES, S. de L.; TAKENATSU, A.P. Pragas. In: IMENES, S.D.L.; ALEXANDRE, M.A.V. (Coord.). Aspectos fitossanitários do crisântemo. São Paulo: Instituto Biológico, 1996. p.13-22. (Instituto Biológico. Boletim Técnico, 5).

BUENO, V.H.P.; VAN LENTEREN, J.C.; SILVEIRA, L.C.P.; RODRIGUES, S.M.M. An overview of biological control in greenhouse chrysanthemums in Brazil. IOBC/WPRS Bulletin, v.26, p.1-5, 2003.

CHAIM, A. Pulverização eletrostática: principais processos utilizados para eletrificação de gotas. Jaguariúna: Embrapa Meio Ambiente, 2006. 17p. (Embrapa Meio Ambiente. Documentos, n.57).

CHAIM, A.; BOTTON, M.; SCRAMIN, S.; PESSOA, M.C.P.Y.; SANHUEZA, R.M.V.; KOVALESKI, A. Deposição de agrotóxicos pulverizados na cultura da maçã. Pesquisa Agropecuária Brasileira, v.38, p.889-892, 2003.

CHAIM, A.; PESSOA, M.C.P.Y.; FERRACINI, V.L. Eficiência da deposição de agrotóxicos obtida com bocal eletrostático para pulverizador costal motorizado. Pesquisa Agropecuária Brasileira, v.37, p.497-501, 2002.

CHAIM, A.; PESSOA, M.C.P.Y.; FERRACINI, V.L. Eficiência de deposição de pulverização em videira, comparando bicos e pulverizadores. Pesticidas: Revista de Ecotoxicologia e Meio Ambiente, v.14, p.41-46, 2004.

CHRISTOFOLETTI, J.C. Pulverização ou aplicação? In: BOLETIM Técnico BT01/99. São Paulo: Teejet South América, 1999. p.2-5.

HISLOP, F.C. Electrostatic ground-rig spraying: an overview. Weed Technology, v.2, p.94-104, 1988.

KABASHIMA, J.; GILES, D.K.; PARRELLA, M.P. Electrostatic sprayers improve pesticide efficacy in greenhouses. California Agriculture, v.49, p.31-35, 1995.

KIYUNA, I.; FRANCISCO, V.L.F.S.; COELHO, P.J.; CASER, D.V.; ASSUMPÇÃ̃, R.; ÂNGELO, J.A. Floricultura brasileira no início do século XXI: o perfil do produtor. Informações Econômicas, v.34, p.14-32, 2004.

MATTHEWS, G.A. Pesticide application methods. $3^{\text {th }}$ ed. Malden: Blackwell Science, 2000. 448p.

SCHRODER, E.P.; LOECK, A.E. Avaliação do sistema de pulverização eletrostática aérea na redução do volume de calda e dosagem do herbicida glifosate. Revista Brasileira de Agrociência, v.12, p.319-323, 2006.

SILVEIRA, R.B.A. Avaliação da qualidade de crisântemos (Dendranthema grandiflora) produzidos em diferentes regiões do Estado de São Paulo. 1998. 114p. Tese (Doutorado) - Escola Superior de Agricultura Luiz de Queiroz, Piracicaba.

$\overline{\text { Recebido em } 30 \text { de outubro de } 2007 \text { e aprovado em } 7 \text { de abril de } 2008}$ 